\title{
Rethinking the Causes of Corruption: Perceived Corruption, Measurement Bias, and Cultural Illusion
}

\author{
Ning $\mathrm{He}^{1}$
}

Received: 21 November 2015/Accepted: 14 March 2016/Published online: 4 April 2016

(C) Fudan University and Springer Science+Business Media Singapore 2016

\begin{abstract}
This paper extends the empirical research on determinants of corruption conducted during the last 20 years. It argues that the apparent correlations between cultural traditions and a country's corruption level are not valid causal inferences. Instead, these correlations are primarily the artifacts of measurement bias on the dependent variable. Corruption measured by perception-based indicators can be conflated with the cultural bias conceived by the respondents whose subjective assessments are the main sources of these indicators. These assessments tend to attribute clean government to specific cultural traditions, for example, Protestantism and a long history of being a democracy. These claims are defended with a series of tests that show first the perception-based indicators of corruption suffer substantial weaknesses, especially systematic measurement bias; second, how the causal mechanisms linking corruption to cultural traditions exhibit inherent theoretical uncertainties; and third, that most of the statistical relationships between cultural traditions and corruption disappear when perception-based indicators of corruption are substituted with an experience-based measurement of corruption. In short, the proposed causal relationships between cultural traditions and corruption are spurious.
\end{abstract}

Keywords Corruption - Corruption perception - Cultural tradition · Measurement bias

Ning He

hening0001@gmail.com

1 Fudan University, 220 Handan Rd., Yangpu District, Shanghai, China 


\section{Introduction}

How do we account for the variance of corruption levels between different countries around the globe? This is one of the most prominent research topics covered by economists, political scientists, and specialists from international organizations in the last 20 years. Since the late 1990s, considerable empirical research on determinants of corruption has emerged, which has produced a body of research findings and policy implications. These studies have propounded various propositions, each of which links corruption to a factor that is claimed to have an effect on the level of corruption. ${ }^{1}$ The factors that have been proposed as determinants of corruption in previous literature can be classified into four different categories: political institutions (for example: institutional democracy, federal structure, freedom of press); development (for example: economic development, educational attainment); economic policy and structure (for example: economic freedom, inflation, economic openness); and cultural traditions (for example: religious traditions, colonial traditions, legal traditions). Among these factors, institutional democracy and decentralization, economic development, and freedom are the most frequently examined determinants of corruption. While the academic circle has accumulated a lot of literature and propositions on the causes of corruption, whether these propositions are valid causal inferences remains a question, since previous studies on determinants of corruption are mostly grounded in perception-based indicators that some researchers have shown generate seriously flawed data. This paper intends to examine the validity of part of the research findings on causes of corruption based on perception-based indicators, which accords with re-examining the final proposition in earlier scholarship, namely the relationship between cultural traditions and corruption.

Cultural explanations of corruption are prevalent in previous literature. For examples, La Porta et al. (1999) found countries that were ethno-linguistically heterogeneous, used French or socialist laws, and those that had high proportions of Catholics or Muslims exhibited inferior government performance. Treisman (2000) extensively examined the relationships between different cultural traditions and corruption and found that countries with Protestant traditions, histories of British rule, and long exposure to democracy were less corrupt. Pellegrini and Gerlagh (2008) also found that a medium-long exposure to uninterrupted democracy is associated with lower corruption levels. Mensah (2014) found that religious traditions as well as national cultural differences had significant effects on perceived levels of corruption. These studies, which commonly assert that colonial tradition, religious tradition, legal tradition, and the democratic tradition are significantly correlated with corruption levels, seem to be well accepted by other scholars, since subsequent studies often take these cultural tradition factors as control variables in their regressions.

\footnotetext{
${ }^{1}$ I have reviewed more than forty pieces of literature published between 1999 and 2015 that used crossnational data to specify the determinants of corruption. In these papers, more than thirty factors were proposed as the determinants of corruption.
} 
While previous research on determinants of corruption repeatedly affirmed the seemingly robust statistical relationships between specific cultural traditions and corruption, this study finds the proposed causal relationships between cultural traditions and corruption are spurious, since, first, in the literature the data used to measure corruption are systematically biased; and second, the causal mechanisms linking corruption to cultural traditions are tenuous.

In this paper, critiques on the cultural explanations of corruption unfold into three interrelated parts. First, I re-examine the quality of the perception-based indicators of corruption and try to demonstrate that the sources and methodologies used for aggregating these indicators are seriously flawed and lead to biased measurements. I argue that these indicators do not assess corruption levels on the basis of objective truth, but rather based on experts' and international business professionals' subjective perceptions. Those perceptions cannot precisely capture the rate of corruption. On the contrary, they are systematically biased by ideology, cultural prejudices, and other factors. That respondents gave a positive evaluation of a country's corruption level could simply be because they found the country had met specific cultural criteria-the main reason that corruption was found to be correlated with cultural traditions.

Second, I re-examine the plausibility of the causal mechanisms linking corruption to different cultural traditions and present evidence that most of the causal mechanisms proposed in previous literature are speculative and cannot weather empirical examination. In fact, they are not effective causal explanations, but rather the artificial ornaments for the statistical findings.

Third, I substantiate my claims by regressing corruption on different cultural traditions. The regression results show that when corruption is measured by the experience-based indicator, which does not have the significant problems that perception-based indicators have, most of the significant correlations between cultural traditions and corruption disappear. I further found that some of the cultural tradition variables are significantly associated with the measurement bias on perception-based indicators of corruption. These findings demonstrate that the statistical associations between cultural traditions and corruption is not robust. The significant correlations between cultural tradition variables and perceived corruption may very well be the result of perceptual biases rather than a reflection of causal relationships.

I mainly focus on four cultural traditions in the empirical examinations, namely colonial tradition, religious traditions, legal traditions, and democratic tradition, all of which were frequently proposed in previous literature as determinants of corruption. In addition, these factors have much in common both conceptually and theoretically. In conception, a country's attributes, called "cultural traditions" in this paper, are defined as a history of that country being dominated by a specific political structure or value system that was in sharp contrast to those of other countries. In other words, cultural tradition is the fixed character of a country. In theory, causal explanations proposed to explain the correlations between different cultural traditions and corruption by previous literature share substantial similarities with each other, in which cultural traditions could influence a country's corruption level by shaping its current political values or policy preferences. 
In empirical testing, I found almost none of the cultural tradition factors was a significant predictor of corruption level, and the proposed causal mechanisms are spurious as well. Based on this evidence, I contend that the apparent statistical associations between cultural traditions and perception-based indicators of corruption are not causal. They may just reflect the biased causal inferences conceived by respondents whose perceptions were the main sources of the measurement of corruption. It is noteworthy that while the proposed causal relations between cultural traditions and corruption are spurious, the theme of this paper is not to prove that no causal relation can exist between any cultural factors and corruption. By questioning already existing research conclusions, this paper aims to highlight the cost of using perception-based indicators to study the determinants of corruption, as well as the cost of deviating from political and economic explanations of corruption.

\section{Weakness of Measurement}

Before the 1990s, it was difficult for researchers to do cross-national comparative studies on the issue of corruption. There was a lack of comparable cross-national data on corruption. Then, thanks to international organizations and private enterprises like Transparency International, the World Bank, and the PRS Group, which have released cross-national data on corruption annually since the 1990s, literature that empirically examines the causes and consequences of corruption on a cross-national level exploded. Cross-national data on corruption have become a highly useful and common tool for researchers to use to study corruption empirically. Nevertheless, most of the corruption data used in previous crossnational studies are perception based rather than experience based. One of the reasons is experience-based data of corruption are very rare especially compared with the perception-based data. During the last 10 years, a body of research has demonstrated that the perception-based measurements of corruption, especially perception-based composite indicators, have substantial limitations and even flaws (Knack 2006; Abramo 2008; Andersson and Heywood 2009; Olken 2009; Razafindrakoto and Roubaud 2010; Thomas 2010). In addition, there has been intense debate on the quality and utility of perception-based cross-national governance indicators (see Kaufmann et al. 2007a, b; Kurtz and Schrank 2007a, b). The warnings and debate did not draw enough of the attention of researchers that focus on the causes of corruption, since most cross-national quantitative studies on the subject published in recent years still employ perception-based composite indexes as the primary measurements of corruption. The most popular of those indexes are the World Bank's Control of Corruption Index (CCI) and Transparency International's Corruption Perception Index (CPI). On the other hand, literature that uses experience-based data of corruption on dependent variables is very rare (see Treisman 2007; Fan et al. 2009). It is understandable that most researchers prefer perception-based composite indicators to other kinds of measurements of corruption in their cross-national studies, as CCI and CPI are well known and have been employed repeatedly in previous work. More importantly, perception-based 
composite indicators ensure researchers have the ability to construct a much larger sample than any other measurement can because they cover many more observed countries and years. Such convenience or advantage seemed to outweigh other considerations in the majority of previous studies. However, concerns about the quality of perception-based data are too pressing to be neglected in cross-national studies on causes of corruption.

In the three parts of this section, I mainly discuss the quality of perception-based composite indicators of corruption, combining research findings included in previous literature and other new empirical evidence discovered in this research. In the discussion, some key questions about the utility of CCI and CPI for crossnational studies are answered. For example, is the large sample constructed from the data of the CCI and CPI really reliable? Are measurements of corruption by the CCI and CPI biased? Do the CCI and CPI capture the actual level of corruption?

\subsection{Sacrificed Comparability}

Perception-based composite indicators of corruption cover far more country-year observations than other measurements. The first set of CPI data measured the corruption level of 41 countries as of 1995. Since then data measuring countries' corruption levels during the prior year has been released annually. CPI's coverage has enlarged since the 41 countries it analyzed in 1995. In 2014 the number of countries covered by this index reached 175 , which accounts for two-thirds of all the countries in the world. CCI is another widely used perception-based composite index of corruption; it covers 1996, 1998, 2000, and all years from 2002 to 2012, taking into account more than two hundred countries. With the abundance of data from CPI and CCI, it is not difficult to construct a time-serial cross-national panel that can reach a sample size of thousands of observations.

Nonetheless, a large sample is not necessarily a good sample. For samples constructed from data from CCI or CPI, there is a tradeoff between sample size and the comparability between different observed values. In fact, too many observed values from CCI or CPI are not comparable with each other. Both the CCI and CPI are composite indicators that aggregate many different sources of corruption data to get the final scores and rankings. These sources define corruption differently from each other, and they came from different institutions that survey different respondents and use different methodologies to construct them. In addition, different sources cover different groups of countries. The aggregation procedures try to make the indicators have a more extensive coverage by combining sources with different coverage together but nonetheless makes different observed values on the CCI and CPI come from different sources or combinations. As Knack (2006) pointed out, composite indexes have no explicit definition, but instead are defined by what goes into them. As a result, with the CCI and CPI, different observed values reflect corruption under different definitions. Put another way, on the CCI and CPI, different observed values represent or measure different objectives, although they are all filed under the name "corruption" rather than the variance of corruption level under a uniform definition. It is not appropriate to compare these values with each 
other because this cannot represent the true variance of corruption levels between different countries.

For example, on CPI 2014, the number of sources used for different countries varies from 3 to 9 . Some country's CPI scores come from only three sources, like the Bahamas and North Korea while, for the United Arab Emirates and Belgium, as many as seven sources are used for the aggregation of their scores. In the strictest sense, scores using three sources are not comparable to those using seven as the definitions of corruption behind the scores differ. In fact, the Bahama's score of 71 and the score of 70 for the United Arab Emirates do not necessarily mean the corruption level gap between the two countries is just one point. If we remove four of the seven sources used for the score of the United Arab Emirates in order to make its sources identical to those of the Bahamas, the corruption gap between the two countries drastically jumps from 1 to 9 points on a 100-point indicator.

Even if the number of sources is the same for two different countries, their scores still might not be comparable with each other. For example, Country $X$ may use Source A, Source B, and Source C, while Country $Y$ may use Source B, Source C, and Source $D$. The number of sources is equal, but the combinations are different. In fact, there are as many as 64 different source combinations for the 175 observed values on CPI 2014, each of which represents a unique definition of corruption. The 175 observed values on CPI 2014 should be divided into 64 different variables, each of which covers a small number of countries. ${ }^{2}$

Moreover, as Treisman (2007) emphasized, since the sources used for the CCI and CPI vary between different years, scores of different years also should not be compared. ${ }^{3}$ It is not appropriate to construct a panel of data using data from the CCI or CPI from different years.

In short, the scores on the CPI and CCI are neither comparable across countries nor comparable over different years. Mixing these values as a single variable goes against the basic principle that a variable should just reflect the variance of only one object. In a relatively large sample comprised of these incomparable values from the CCI or CPI, the true variation in corruption levels between different countries is distorted to some extent. The main reason for the loss of comparability between different observed values is the aggregation of so many different sources. Just as Knack (2006) suggested, it is more appropriate to use data from a single source rather than a composite indicator.

\subsection{Measurement Bias}

The perception-based measurement of corruption is very likely to be biased due to the intrinsically subjective nature of perceptual assessment, which is highly susceptible to being influenced by irrelevant factors. In the subjective evaluation and comparison of corruption levels between different countries, whoever the

\footnotetext{
2 The combination with the maximum coverage of countries on CPI 2014 merely covers 16 countries. There are 35 combinations each of which only covers one country, and the scores of these countries are never comparable with any other scores or values on CPI 2014.

3 Transparency International itself also emphasized on its website that "CPI scores before 2012 are not comparable over time." See http://www.transparency.org/cpi2014/in_detail\#myAnchor7.
} 
respondent is (expert, businessperson, or ordinary person), he or she is supposed to master the positive knowledge about the overall state of corruption in several different countries. This is almost impossible. Although some of the respondents may have had personal experiences with corrupt behavior, most of them can only provide anecdotal evidence-merely a small part of the big picture. As a result, when respondents were asked to evaluate the corruption level in one or several countries, they had to appeal to these loose anecdotes for their evaluations rather than appealing to systematic evidence of corrupt transactions occurring. The anecdotes revolve around factors that the respondents themselves regard as related to a country's corruption level, and they tend to grade corruption levels based on the existence or extent of these factors. For example, if someone believes that democratic countries are less corrupt, he or she may well rate a democratic country's corruption level as low.

It seems quite arbitrary which factors respondents use as their reference for corruption levels if we acknowledge that different people perceive corruption levels from different perspectives. However, it is true that most of the respondents have common perspectives. ${ }^{4}$ Some of them are right, which means the actual corruption level is related to the factors considered by the respondents; while some of them are wrong, which means the factors considered are not really associated with the actual corruption level. ${ }^{5}$ When respondents view corruption levels from the wrong perspectives, the resulting measurement reflects variations that are irrelevant but nevertheless highly correlated with some other factors. These variations are just systemic biases in the measurement of corruption levels, which are very common in perception-based measurements of corruption.

Some previous studies have already shown the existence of such systemic biases in perception-based measurements. Respondents' perceptions are often susceptible to irrelevant factors. For example, Razafindrakoto and Roubaud (2010) surveyed 350 experts in eight African countries on their opinions about the corruption levels in these countries. The analysis found that these experts' assessment of corruption levels was ideologically biased. Experts as respondents who were in favor of the withdrawal of state and liberalization significantly overestimated the extent of corruption, and experts who felt there were too many civil servants more often overestimated the extent of corruption. Kurtz and Schrank (2007a) examined whether government effectiveness, measured by one of the six perception-based Worldwide Governance Indicators, is susceptible to recent economic performance, the result of which has significant implications on the validity of perception-based measurement of corruption. ${ }^{6}$ They found that a country's government effectiveness could be well

\footnotetext{
${ }^{4}$ For example, Kurtz and Schrank (2007a) argued that the Worldwide Governance Indicators, which are all perception-based, are commonly susceptible to policy preference, cultural blinders and recent economic growth.

5 Even though the respondents capture the factors that are really associated with corruption level, it does not necessarily mean they can give an accurate measurement since they cannot accurately predict to what extent these factors are associated with corruption level, and there are many different factors to consider.

${ }^{6}$ Because both the control of corruption index (CCI) and the measurement of government effectiveness come from the dataset of the Worldwide Governance Indicators, and they are both perception-based indicators sharing very similar sources and methodologies of aggregation.
} 
predicted by the country's recent GDP growth rate, even though theoretically growth cannot have such an instantaneous effect on government effectiveness. The reason is that the respondents unreasonably perceive countries growing fast as countries governed well, which makes the perception-based measurement of government effectiveness biased.

Perception-based measurements of corruption are also susceptible to sample selection bias when the sample of respondents, whose assessments of corruption are the primary sources, is not representative enough. Respondents included in the sample may commonly overestimate or underestimate the corruption level in specific countries. For example, as Kurtz and Schrank (2007a) argued:

They systematically censor the opinions of former investors who did not succeed in the marketplace, or potential investors who were deterred from entering local markets by pervasive malgovernance or corruption itself... By contrast, investors who are competing successfully in the marketplace, and therefore show up in the surveys, may be doing so precisely because they are the beneficiaries of corruption and cronyism-and are therefore, unlikely to report it accurately. And where malgovernance is effectively reported, this may well be because it is not pervasive enough to create sufficiently strong distortions in firm-level survival or investor behavior to induce selection bias.

Following the example of Kurtz and Schrank's work (2007a), I try to empirically examine whether CCI and CPI suffer the irrelevant factor bias and the sample selection bias. First, I hypothesize that, like the perception-based measurement of government effectiveness, CCI and CPI are also contaminated by respondents' perception of recent economic growth, which does not have an instantaneous effect on corruption level. Second, I hypothesize that the measurement of corruption levels on CCI and CPI are affected by survey respondents' country-background distribution, which is a result of sample selection. As Andersson and Heywood (2009) pointed out, the survey respondents of these indicators are mainly Western business leaders and experts who do not evenly distribute in all countries covered by the indicators. When international businesspeople were asked to compare the corruption levels of their investment destinations and their home countries, they tended to exaggerate the gap of corruption levels between the two countries, since the two countries do not have equal opportunities to be observed. The businesspeople have more chances to observe or even engage in corrupt transactions in their investment destinations compared with their home countries, which leads to underestimation of the home countries' corruption level, or overestimation of the investment destinations' corruption level. The more likely businesspersons from a certain country are chosen as survey respondents, the relatively better this country is evaluated on corruption level. Obviously, this makes the measurement of corruption biased. 
I regress $\mathrm{CCI}$ and $\mathrm{CPI}$, respectively, on recent GDP growth rates and FDI outflows ${ }^{7}$ with income level, regime type and economic freedom being controlled. For comparison, I also regress an experienced-based indicator of corruption from Global Corruption Barometer (GCB) on these variables. ${ }^{8}$ The results in Table 1 show the recent GDP growth rate is a significant predictor of both CCI and CPI, while the coefficient of recent GDP growth rate is not significantly different from zero when the dependent variable becomes the experience-based indicator of corruption. It can be explained that respondents commonly take the recent economic situations as reference when they are asked to rate a country's corruption level although it is quite spurious to infer that the two factors have a causal relationship with each other. It can be argued that corruption can affect economic growth as reversed to the previous hypotheses, which means recent economic growth and corruption can be reasonably correlated in the manner that corruption has an effect on recent economic growth. Specifically, a clean government leads to high economic growth. However, the causal relationship between corruption level and economic growth is not as simple as of being presented in Table 1 if such a causal relationship exists at all. The relationship between corruption and growth always depends on some other factors as well as the type of corruption, and it is possible that specific types of corruption can lead to economic growth under specific circumstances. In fact, a linear association between corruption level and recent economic growth is not true in either direction.

Similarly, FDI outflow is significant of both CCI and CPI, but not for the experienced-based indicator. It proves that the selection bias of respondents in the surveys, which CCI and CPI are derived from, substantially bias the result of the measurement.

Some researchers tried to validate the perception-based measurements of corruption in a correlative manner (see Wilhelm 2002). They argued that perception-based indicators are highly correlated with each other, which suggests that these indicators have captured the common objective despite the different sources and methodologies they came from (Treisman 2000). However, there are as least two prerequisites for the inference that high correlation is an accurate signal of measurement validity. First, the sources of the two indicators must be independent of each other. In principle, they should not share the same sources. Second, the measurement errors of these indicators are supposed to be random. High correlation cannot support validity if measurement errors of the two indicators are systematic, since the errors could be correlated.

\footnotetext{
7 Since the data of survey respondents' background distribution is not available, I find a proxy for it, which is the foreign direct investment (FDI) outflow. When a country (Country A, for example) has more FDI outflow, there are more businesspersons from Country A investing to other countries, hence international businesspersons from Country A have more chances to be selected and surveyed, and survey respondents' backgrounds have a higher probability of being Country A. While in other countries where there are less FDI outflows, businessmen from these countries have less chance to be surveyed. According to previous hypothesis, the corruption level of countries like Country A is more likely to be underestimated on CCI and CPI.

${ }^{8}$ This experienced-based measurement of corruption will be introduced in details in the fourth section.
} 
Table 1 Economic growth rate, FDI outflow, and perceived corruption (OLS regression)

\begin{tabular}{|c|c|c|c|c|c|c|}
\hline $\begin{array}{l}\text { Dependent } \\
\text { variable }\end{array}$ & $\begin{array}{l}\text { I } \\
\text { CPI, } 2010\end{array}$ & $\begin{array}{l}\text { II } \\
\text { CCI, } 2010\end{array}$ & $\begin{array}{l}\text { III } \\
\text { GCB, } 2010\end{array}$ & $\begin{array}{l}\text { IV } \\
\text { CPI, } 2010\end{array}$ & $\begin{array}{l}\text { V } \\
\text { CCI, } 2010\end{array}$ & $\begin{array}{l}\text { VI } \\
\text { GCB, } 2010\end{array}$ \\
\hline $\begin{array}{l}\text { GDP growth } \\
\operatorname{rate}_{(t-1)}\end{array}$ & $\begin{array}{r}0.075^{* *} \\
(0.031)\end{array}$ & $\begin{array}{r}0.032 * * \\
(0.014)\end{array}$ & $\begin{array}{l}0.003 \\
\quad(0.003)\end{array}$ & & & \\
\hline $\begin{array}{l}\text { Ln (FDI } \\
\text { outflow) }\end{array}$ & & & & $\begin{array}{r}0.224 * * * * \\
(0.074)\end{array}$ & $\begin{array}{r}0.103 * * * * \\
(0.033)\end{array}$ & $\begin{array}{c}-0.002 \\
(0.007)\end{array}$ \\
\hline $\begin{array}{l}\text { Ln }(\text { GNI per } \\
\text { capita) }\end{array}$ & $\begin{array}{r}0.873 * * * \\
(0.172)\end{array}$ & $\begin{array}{r}0.361^{* * * *} \\
(0.080)\end{array}$ & $\begin{array}{c}-0.127 * * * \\
(0.018)\end{array}$ & $\begin{array}{l}0.355 \\
\quad(0.268)\end{array}$ & $\begin{array}{l}0.145 \\
\quad(0.120)\end{array}$ & $\begin{array}{c}-0.131^{* * * *} \\
(0.027)\end{array}$ \\
\hline $\begin{array}{l}\text { Institutional } \\
\text { democracy }\end{array}$ & $\begin{array}{r}0.107 * * * \\
(0.033)\end{array}$ & $\begin{array}{r}0.054 * * * \\
(0.015)\end{array}$ & $\begin{array}{r}-0.002 \\
(0.003)\end{array}$ & $\begin{array}{r}0.088 * * * * \\
(0.034)\end{array}$ & $\begin{array}{r}0.045^{* * * *} \\
(0.015)\end{array}$ & $\begin{array}{c}-0.004 \\
(0.003)\end{array}$ \\
\hline $\begin{array}{l}\text { Business } \\
\text { freedom }\end{array}$ & $\begin{array}{r}0.055^{* * * *} \\
(0.012)\end{array}$ & $\begin{array}{r}0.029 * * * \\
(0.006)\end{array}$ & $\begin{array}{r}-0.002 \\
(0.001)\end{array}$ & $\begin{array}{r}0.065^{* * * *} \\
(0.013)\end{array}$ & $\begin{array}{r}0.032 * * * * \\
(0.006)\end{array}$ & $\begin{array}{r}-0.002 \\
(0.001)\end{array}$ \\
\hline No. obs. & 86 & 87 & 87 & 68 & 69 & 69 \\
\hline$R^{2}$ & 0.69 & 0.70 & 0.69 & 0.72 & 0.73 & 0.67 \\
\hline
\end{tabular}

The data of CPI (Corruption Perception Index) and GCB (Global Corruption Barometer) come from Transparency International; the data of CCI (Control of Corruption Index) come from WGI data set by the World Bank; the data of GDP growth rate, FDI outflow, and GNI per capita come from WDI dataset by the World Bank; the data of institutional democracy come from the Polity IV dataset; the data of business freedom come from The Heritage Foundation. Observation unites in the sample are countries

$* * * p<0.01 ; * * p<0.05 ; * p<0.10$

Unfortunately, CCI and CPI meet none of the two prerequisites. In fact, the high correlation between CCI and CPI is just a reflection of them sharing a considerable amount of the same sources, which are interdependent to each other. For example, of the 13 sources used for the aggregation of CPI 2013, ten of them can be found in the list of sources used for the CCI. This explains why CCI and CPI are highly correlated with each other, no matter how different the aggregating methodologies are. Knack (2006) also pointed out expert assessors in these sources often consult each other, and that some sources may be free-riding other's assessments. In addition, as discussed and examined above, perception-based indicators share paralleled systematic bias due to the intrinsic nature of perceptual assessment and the sample selection bias. Hence, high-correlation is not a good argument for the validity of perception-based measurement of corruption.

\subsection{Poor Representation}

The extent to which perception-based indicators of corruption actually represent corruption levels must also be questioned. Previous studies offer unsatisfying answers. Some studies have already shown that perceived corruption is a poor gauge of the actual level of corruption. Olken (2009) empirical study in Indonesia showed that villagers' perception of corruption contained relatively nuanced information about actual corruption levels. Perceptions appeared to capture only one way of hiding corruption while not capturing other elements of corruption. Abramo (2008) used the data from Global Corruption Barometer 2004, an experience-based measurement of corruption, to predict people's perception of corruption. The result 
also showed that perceived corruption was not a good predictor of experienced corruption. Those who had experienced corruption did not report a significantly higher perception of corruption than those who had not, and the relationship between corruption experience and corruption perception varied between rich and poor countries.

The correlations between perception-based indicators of corruption and experience-based indicators of corruption are also consistent with these findings. For example, the coefficient of correlation between CCI 2010 and CPI 2010 is 0.99, but they are not highly correlated with the experience-based data from GCB 2010, since the coefficients are just 0.67 and 0.65 . A coefficient above 0.6 indicates a strong correlation between two independent variables, but not for two indicators trying to measure the same objective. ${ }^{9}$ It is true that a subjective indicator and an objective indicator can define corruption in distinguishable ways. The bribery rate of GCB data is more of a reflection of the extent of administrative corruption while subjective indicators, like CCI, as the World Bank claims, also aim to take state capture into consideration when producing the indicator. However, the truth is subjective indicators like CCI exhibit no substantial advantage in measuring state capture compared with objective indicators. Using a democracy indicator as a proxy for state capture, I found that correlation between CCI and the democracy indicator was 0.47 , and correlation between GCB and the democracy indicator was 0.43 . Subjective indicators and objective indicators predict state capture to similar extent, and neither of them gauges state capture effectively. Hence, at least we can say the substantial difference between subjective indicators and objective indicators is not likely the result of different definitions of corruption between them.

Since perceived corruption is a poor gauge of corruption reality, the results of regressions using perception-based indicators of corruption as dependent variables could be rather misleading when these indicators are regarded as measurements of corruption reality. Olken (2009) study shows that the same factors can affect corruption perception and corruption reality very differently. For example, ethnic heterogeneity is associated with higher level of perceived corruption, while this association became negative when perceived corruption is replaced by the actual level of corruption.

It can be shrewdly argued that perceived corruption and corruption reality are essentially two different things. In other words, perception is perception, which is important no matter how far away it deviates from the corruption realities, and one should not evaluate the perceived corruption indicators using experience-based measurements as a benchmark. Nevertheless, if the perception-based indicators do not intend to capture the reality of corruption, what is the value of these indicators? Why should we regress them on the factors that are theoretically related to corruption activities? It should be noted that what we want to know is the actual

\footnotetext{
${ }^{9}$ It could be argued that the CCI and CPI define corruption differently from what GCB defines as corruption, which explains why they are not highly correlated with GCB. However, it is odd that the CCI and CPI happen to define corruption so similarly while both define corruption so differently from the GCB. Actually, these similarities and differences are determined by methodology rather than definition. Neither the CPI nor CCI has an explicit definition on what they are measuring, since they aggregated so many different sources.
} 
occurrence of corruption rather than some hint of it. To achieve this, researchers should gauge it as accurately as possible. Unfortunately, usually we mistake perceived corruption for corruption reality and pretend that it is not a mistake needing to be corrected.

\section{Theoretical Uncertainty}

In this section, the theoretical uncertainties of the causal inference that cultural traditions have effects on a country's corruption level are discussed. Previous studies commonly presumed that some kinds of cultural traditions can shape specific social values or policy preferences that disincentivize corruption. However, I find the proposed social values or policy preferences often exhibit no significant difference between countries belonging to different categories of cultural traditions, or the difference of social values is not the result of cultural traditions, which means the proposed "effects" of cultural traditions on corruption may not be valid.

A country's attributes, called "cultural traditions" in this paper, are defined as a history of that country being dominated by a specific political structure (example: British colonial rule and democratic rule) or value system (example: Protestantism) that was in sharp contrast to those of other countries. In other words, cultural tradition is a country's fixed character that rarely changes over time. The relationship between cultural factors and economic development has long been a popular research topic since the publication of Max Weber's The Protestant Ethic and the Spirit of Capitalism, which inspired scholars to focus on the importance of culture in the development of a society. Scholars who focus on the determinants of corruption have also taken cultural factors into consideration. La Porta et al. (1999) contributed an original work on this line of research. Their cross-national study found countries that were ethno-linguistically heterogeneous, used French or socialist laws, or had high proportions of Catholics or Muslims in the population exhibited inferior governmental performance. Then a sophisticated comparative study on the causes of corruption by Treisman (2000) extensively examined the relationships between different cultural traditions and corruption. He found that countries with Protestant traditions, histories of British rule, and long exposure to democracy were less corrupt. Subsequently, Pellegrini and Gerlagh (2008) reaffirmed that a medium-long exposure to uninterrupted democracy was associated with lower corruption levels. Mensah (2014) also found that religious traditions as well as national cultural differences had significant effects on perceived levels of corruption.

In the following parts of this section, I will re-examine the theoretical plausibility of these propositions, including the proposed causal relationships between corruption and the British colonial tradition, religious traditions, legal traditions, as well as democratic tradition. Evidence of theoretical uncertainties between corruption and these cultural traditions is presented. 


\subsection{British Colonial Tradition}

In a comparative study of the causes of corruption, Treisman (2000) found a significant relationship between colonial history and current corruption levels. Specifically, he found that countries with histories of British rule were less corrupt. A series of subsequent studies by other scholars tested this relationship (Serra 2006; Pellegrini and Gerlagh 2008). As Treisman argued, in Britain and its former colonies there was an obsessive focus on the procedural aspect of law, while in other cultures social order was associated not so much with adherence to procedures as with respect for hierarchy and the authority of officials. This difference of political culture leads to the different levels of corruption between former British colonies and other countries.

However, it is doubtful whether political culture is so distinctive between former British colonies and other countries. Colonial history may just capture the initial differences of political culture between different countries. Political values could have disseminated in waves of democratization and globalization, making former British colonies and other countries not look so different. Hence, whether the proposed difference in political cultures exists between former British colonies and other countries needs to be empirically examined. Specifically, do citizens in former British colonies respect legal procedure more than citizens in other countries? Do the former respect hierarchy or authority less than the latter?

To measure the hierarchical and procedural preference of countries' political cultures, I employ the data from the World Value Survey (WVS). Statistics from responses to four questions are used as measurements in order to show whether a country's political culture is more hierarchical or more procedural. The questions are:

Question 1 Having a strong leader who does not have to bother with parliament and elections is good

Question 2 Having a democratic political system is good

Question 3 People obeying their rulers is an essential characteristic of democracy

Question 4 People choosing their leaders in free elections is an essential characteristic of democracy

Then political culture variables, which reflect the percentage of respondents in each country that agree with the statements in the questions, are regressed on the dummy variable former British colony, with degree of democracy and education level being controlled. Regression results in Table 2 show that none of the political culture variables can be significantly predicted by whether or not a country is a former British colony. On the other hand, answers for Question 3 can be predicted by a country's education level. Citizens with more education are less inclined to obey their rulers even though the regime context is democracy. In addition, answers for Question 4 can be predicted by a country's level of democracy. People living in countries with higher levels of democracy attach more importance to free elections. 
Table 2 British colonial tradition and political culture (OLS regression)

\begin{tabular}{lllll}
\hline Independent variable & \multicolumn{4}{l}{ Dependent variable: percentage of respondents agreeing with } \\
\cline { 2 - 5 } & Question 1 & Question 2 & Question 3 & Question 4 \\
\hline Former British colony & $-7.376(5.907)$ & $-0.118(2.485)$ & $6.148(4.667)$ & $-3.552(2.945)$ \\
Institutional democracy & $-0.559(0.548)$ & $0.053(0.230)$ & $-0.475(0.433)$ & $0.827 * * *(0.273)$ \\
Education level & $0.722(1.341)$ & $-0.135(0.564)$ & $-3.111^{* * *(1.059)}$ & $0.155(0.668)$ \\
No. obs. & 51 & 51 & 51 & 51 \\
$R^{2}$ & 0.06 & 0.00 & 0.30 & 0.24 \\
\hline
\end{tabular}

Data on dependent variables come from World Value Survey; Data on independent variables come, respectively, from ICOW Colonial History Data Set, Polity IV, Barro and Lee's dataset on education. Observation unites in the sample are countries

$* * * p<0.01 ; * * p<0.05 ; * p<0.10$

\subsection{Religious Tradition}

In The Protestant Ethic and the Spirit of Capitalism, Weber argued that the Protestant work ethic was an important force behind the unplanned and uncoordinated emergence of modern capitalism (McKinnon 2010). However, a series of recent empirical studies carefully examined this argument and found that the effect of religion on economic development is nonexistent (see Becker and Woessmann 2009; Cantoni 2015; Bai and Kung 2015).

In the past two decades, religious factors were also introduced into the study of the determinants of governance. In their cross-national study, La Porta et al. (1999) found that countries have high proportions of Catholics or Muslims exhibit inferior government performance. Subsequent to their work, some researchers also found that the share of Protestants in a country is negatively associated with its corruption level (Treisman 2000; Sandholtz and Koetzle 2000; Serra 2006; Pellegrini and Gerlagh 2008; Mensah 2014). As for the theoretical mechanisms connecting religion and corruption, La Porta et al. argued that "Catholic and Muslim countries would be viewed by the adherents of cultural theories as being more interventionist than Protestantism," which makes these countries more corrupt than Protestant countries; while Treisman (2000) argued that Catholic and Islamic countries are more corrupt because their dominant religions are more hierarchical, which rarely challenges office-holders. These arguments will be examined, respectively.

To empirically examine the first causal mechanism, which takes interventionism as a mediating variable, the correlations between religious traditions and business freedom are presented (see Table 3).

Correlations between a country's religious tradition and its degree of interventionism fail to prove moderate or strong associations, which means interventionism may not be a valid mediating variable linking corruption to religious traditions.

To test the second causal explanation, which also takes political culture as a mediating variable, I again use the questions in Sect. 3.1 to measure the hierarchical preference of countries' political cultures. Firstly, $T$ statistics are calculated to compare the hierarchical preference between countries dominated by different 
Table 3 Correlations between religious traditions and business freedom

\begin{tabular}{llll}
\hline & \multicolumn{2}{l}{ Business freedom } & \\
\cline { 2 - 4 } \cline { 2 - 3 } Correlation & $T$ value & No. obs. \\
\hline Percentage of protestant population & 0.05 & 0.62 & 94 \\
Percentage of catholic population & -0.02 & 0.83 & 94 \\
Percentage of muslim population & -0.11 & 0.31 & 94 \\
\hline
\end{tabular}

The data of religious traditions come from Pew Research Center; the data of business freedom come from Heritage Foundation. All data reflect the situation of the year 2010. Observation unites in the sample are countries

Table 4 Religious traditions and political culture (OLS regression)

\begin{tabular}{lllll}
\hline Independent variable & \multicolumn{4}{l}{ Dependent variable: percentage of respondents agreeing with } \\
\cline { 2 - 5 } & Question 1 & Question 2 & Question 3 & Question 4 \\
\hline Catholic religious tradition & $-0.350(6.821)$ & $1.619(2.815)$ & $-0.964(5.388)$ & $-1.061(3.394)$ \\
Islamic religious tradition & $1.793(8.327)$ & $0.367(3.437)$ & $2.385(6.578)$ & $0.591(4.143)$ \\
Institutional democracy & $-0.527(0.618)$ & $0.009(0.255)$ & $-0.353(0.488)$ & $0.865^{* * *}(0.307)$ \\
Education level & $1.056(1.523)$ & $-0.061(0.629)$ & $-3.152^{* * *(1.203)}$ & $0.272(0.758)$ \\
No. obs. & 51 & 51 & 51 & 51 \\
$\mathrm{R}^{2}$ & 0.03 & 0.01 & 0.28 & 0.22 \\
\hline
\end{tabular}

Data on dependent variables come from World Value Survey; Data on independent variables come, respectively, from Global Religious Futures by Pew Research Center, Polity IV, Barro and Lee's dataset on education. Observation unites in the sample are countries

$* * * p<0.01 ; * * p<0.05 ; * p<0.10$

religions. The result shows that people in Catholic countries do not share a value that is more hierarchical than people from non-Catholic countries. However, people in Islamic countries do feel it more necessary to obey rulers than people in nonIslamic countries. People from Islamic countries also attach less importance to free election as a necessary characteristic of democracy. In order to specify whether it is Islamic cultural tradition that leads to this difference on political value, rather than other relevant country attributes, multiple linear regressions are conducted. Responses from different countries' populations for Question 3 and Question 4 are regressed on the dummy variable Islamic country, with democratic level and education level being controlled. Regression results in Table 4 show that the significant correlations between Islamic cultural tradition and hierarchical political culture disappear when level of democracy and education level are controlled. That people in Islamic countries feel more of a need to obey their rulers is because they are less educated than people in non-Islamic countries (7.2 years of formal education on average vs. 10 years on average ${ }^{10}$ ), considering that education significantly decreases people's belief in obeying rulers. Similarly, that people in Islamic countries attach less importance to free elections is because Islamic

\footnotetext{
${ }^{10}$ Sample is the same as the one used for regressions in Table 4, and $T$ statistic is significant.
} 
countries are commonly much more autocratic that non-Islamic countries $(0.2$ on Polity score vs. 7.1 on Polity score ${ }^{11}$ ), considering that democratic regimes significantly increase people's identification with free election. Hence, the observation that Islamic countries have a more hierarchical political culture is not a causal inference, but rather the result of a coincidence between Islamic cultural tradition and other country attributes. In addition, the association between Catholic religious tradition and hierarchical preference is not significant either in multiple regressions. Hence, I would argue that the proposed causal mechanisms linking corruption to Catholicism or Islamism are not valid.

\subsection{Legal Tradition}

In their comparative study of the determinants of government performance, La Porta et al. (1999) found countries using French or socialist laws exhibit inferior government performance. Although the relationship between legal tradition and corruption has been shown to be weak (see Treisman 2000; Lederman et al. 2005; Pellegrini and Gerlagh 2008), this proposition is quite influential. A great deal of subsequent literature takes legal traditions as control variables in the study of the determinants of governance. The reason why countries of different legal traditions may exhibit different levels of governance is, as La Porta and his colleagues argued:

Socialist law is a manifestation of the state's intent to create institutions to maintain its power and extract resources, without much regard for protecting the economic interests or the liberties of the population. A civil law tradition can be taken as a proxy for an intent to build institutions to further the power of the state, although not to the same extent as in the socialist tradition. Co mmon law systems reflect to a much greater extent the intent to limit the power of the sovereignty, which put much emphasis on property rights.

According to their argument, countries that use socialist laws have the most interventionist governments, followed by countries that use civil laws and then by common law countries. The extent of political freedom in these countries also goes in the same order.

It is plausibly true that governmental intervention and political freedom do affect the level of corruption in a country (Gerring and Thacker 2005; Brunetti and Weder 2003). In Table 5, the tests show that countries using British common law are no less interventionist either politically or economically compared with other countries. However, it is true that countries using French civil law and countries using socialist law are more interventionist. In addition, countries using German civil law and countries using Scandinavian law are less interventionist both politically and economically. The following sections will empirically examine whether different types of legal traditions have different effects on levels of corruption.

11 Ibid. 
Table 5 The differences of business freedom and freedom of press between countries of different legal traditions

\begin{tabular}{llllll}
\hline & \multicolumn{4}{l}{ Margins of freedom score compared with countries under other law systems } \\
\cline { 2 - 6 } & $\begin{array}{l}\text { Common law } \\
\text { countries }\end{array}$ & $\begin{array}{l}\text { French law } \\
\text { countries }\end{array}$ & $\begin{array}{l}\text { Socialist law } \\
\text { countries }\end{array}$ & $\begin{array}{l}\text { German law } \\
\text { countries }\end{array}$ & $\begin{array}{l}\text { Scandinavian law } \\
\text { countries }\end{array}$ \\
\hline $\begin{array}{l}\text { Business } \\
\text { freedom }\end{array}$ & $1.19(0.64)$ & $-7.30(4.20)$ & $-5.31(2.70)$ & $15.55(4.78)$ & $5.84(7.63)$ \\
$\begin{array}{l}\text { No. obs. } \\
\begin{array}{c}\text { Freedom of } \\
\text { press }\end{array}\end{array}$ & $-1.04(0.42)$ & $-7.63(3.31)$ & $-7.07(2.71)$ & $22.76(5.29)$ & $34.06(7.54)$ \\
\begin{tabular}{l} 
No. obs. \\
\hline
\end{tabular} & 357 & 357 & 357 & 351 & 351 \\
\hline
\end{tabular}

Values in the parentheses are the $T$ values. The data of legal system come from Porta et al. (1999); data of business freedom come from Heritage Foundation; data of freedom of press come from freedom house. Observation unites in the sample are countries

\subsection{Democratic Tradition}

In recent years, researchers who focus on the causes of corruption have seen democracy not just as a specific arrangement of political institutions, but also as a culture or tradition that derives from the cumulative experience of being a democracy. Some studies found a cumulative democratic experience is more important for altering corruption levels than merely having democracy as the current political institution (see Treisman 2000). In previous literature, the proposed relationship between democracy and corruption varies in terms of the measurement of democracy and the form of causality, which is classified as four different types in the following discussion.

The first type of causal relationship between democracy and corruption emphasizes democracy as an existing political institution that can provide incentive to hold public officials accountable. Numerical scores, like those from Freedom House and the Polity IV Project, are used to measure the current level of democracy in different countries. Researchers hypothesized a linear relationship between current democracy levels and corruption (see Table 6), while few of them have shown any both significant and robust results (see Chowdhury 2004; Kolstad and Wiig 2015). Indeed, most of the results are significant but not robust, and the significance often disappears once income level is controlled. A more sophisticated type of relationship between democracy and corruption assumes the form of causality is not linear. Several studies found that the corruption level increases when a country has a medium level of democracy, while both lower and higher democracy levels saw a less corrupt situation (see Montinola and Jackman 2002; Treisman 2007). Sung (2004) found that corruption level is a cubic function of current democracy level. Saha et al. (2014) found the relationship between current democracy level and corruption was significant only if the democracy level reached a specific threshold.

Some studies found that the "democratic culture" was also or even more important for preventing corruption. Some scholars capture "democratic culture" 
Table 6 Literature on different types of relationship between democracy and corruption

\begin{tabular}{cll}
\hline & Corruption & \\
\cline { 2 - 3 } & Linear relationship & Non-linear relationship \\
\hline $\begin{array}{c}\text { Democratic } \\
\text { institution }\end{array}$ & $\begin{array}{c}\text { Goldsmith (1999), Sandholtz and Koetzle } \\
\text { (2000), Chowdhury (2004), Bohara et al. } \\
\text { (2004), Serra (2006), Treisman (2007) } \\
\text { and Kolstad and Wiig (2015) }\end{array}$ & $\begin{array}{c}\text { Montinola and Jackman (2002) and } \\
\text { Treisman (2007) }\end{array}$ \\
$\begin{array}{c}\text { Democratic } \\
\text { tradition }\end{array}$ & $\begin{array}{c}\text { Sandholtz and Koetzle (2000), Bohara et al. } \\
\text { (2004), Ledermanet al. (2005) and }\end{array}$ & $\begin{array}{c}\text { Treisman (2000), Bohara et al. (2004), } \\
\text { Serra (2006), Treisman (2007), Pellegrini } \\
\text { and Gerlagh (2008) and Rock (2009) }\end{array}$ \\
\hline & & \\
\hline
\end{tabular}

with a dummy variable that reflects whether a democratic regime had lasted uninterruptedly for a specific span of time. For example, Treisman (2000) found countries that had an uninterrupted democracy from 1950 to 1995 are significantly less corrupt than others. Other literature captured "democratic culture" by counting the number of consecutive years a country was an uninterrupted democracy (Sandholtz and Koetzle 2000; Lederman et al. 2005; Treisman 2007; Rock 2009). A county can be regarded as having a more profound democratic culture if it experienced a longer period of democracy. Some researchers even aggregated together all the democracy scores a country gained during a specific time period as the measurement of this country's democratic culture (Bohara et al. 2004; Rock 2009). Both linear and nonlinear relationships between democratic culture and corruption have been found in these studies (see Table 6). Rock (2009) even found that corruption level is a quadratic function of the cumulated experience with democracy.

As for the causal mechanism linking democracy and corruption, Sandholtz and Koetzle (2000) argued that democracy as institution and democracy as a culture curb corruption in different ways. A specific normative orientation comes with democratic culture that could help prevent the occurrence of corruption. As they argue:

We assume that in established democracies the following normative orientations are widely shared: all citizens should enjoy equality of opportunity before the state; public office should not be a vehicle for private enrichment; and public office entails a duty to the collective will.

According to this argument, citizens living under long-established democracies tend to be less tolerant of corruption compared with other types of regimes. However, even in autocracies corruption can be a deeply unwelcome social phenomena that undermines the legitimacy of ruling powers. For example, in China social surveys find that prevalent dissatisfaction with official corruption significantly weakens the Chinese Communist Party's legitimacy and popular support (Zhong and Chen 2013). In China, about $78 \%$ of the respondents did not think accepting a bribe is justifiable, while in India, a democracy that has lasted for more than 60 years, just $70 \%$ of the respondents did not think taking a bribe is justifiable (World Value Survey Wave 6). A more extensive sample that covers 59 countries 
from the World Value Survey also shows that tolerance to corruption, which is measured by the percentage of respondents who think accepting a bribe is justifiable, is almost the same between long-established democracies and other types of regimes. In most countries people are conformably intolerant to corruption.

Since long-established democracies exhibit no unique and superior social norm that could help deter corruption, a democratic tradition could have no effect on corruption. The most untarnished countries in the world are often those with a long tradition of democracy, while at the same time they are commonly more politically stable, with higher incomes, higher educational attainment, and less interventionism in their markets, all of which contribute to the prevention of corruption. The apparent association between democratic tradition and corruption may just reflect the effects of the other factors on corruption, rather than the effect of democratic experience itself.

\subsection{Cultural Factors Versus Other Factors}

Previous discussions try to demonstrate that the causal mechanisms linking corruption to colonial traditions, religious traditions, legal traditions, and democratic traditions are not as valid as expected because social values and public policy can be independent from these traditions. Most assumptions that people from different cultures are fundamentally divided on political values or public policy are just stereotypes, for example, the belief that Islamic countries are more in favor of interventionism. Although specific social values are sometimes different between countries of different cultural traditions, it is not the cultural tradition but rather the difference of institution and development that leads to the distinction, as shown previously in this paper. Even if cultural background does have effects on people's acceptance of corruption, this effect is very unstable. For example, experiments done by Barr and Serra (2010) found that participants' cultural background was not a robust predictor of their propensities to engage in bribery, and individuals' norms, values and beliefs relating to corruption may change following a change in context. It could be inferred that, even if countries of different cultural traditions have different social norms initially, the norms could change as the political and economic context changes. It is inappropriate to conclude that social norms are fixed with cultural traditions.

The evidence has shown that cultural traditions may not be effective explanatory factors of corruption. On the other hand, institutional and economic factors still account for much of the variance in corruption level between different countries. The cultural explanations of corruption indicate that some countries are born to be corrupt or clean in their governments, while many cases have shown that the corruption situation in a country could exhibit remarkable change following institutional change and economic change. For example, the United States, whose government is among the cleanest in the world today, used to be no less corrupt than most of today's transitional economies and developing regions in its early stage of modernization (Glaeser and Goldin 2007). Asian countries like Japan, South Korea, and Taiwan all experienced a transition from corrupt to clean following their economic takeoff and institutional change. The cities of Hong Kong and Singapore 
took just two decades to transform themselves from being among the most corrupt governments to the global model of the construction of a clean government. In all these cases, social and economic development, as well as institutional improvement played crucial roles in the process of corruption prevention.

Previous cross-national quantitative studies have repeatedly tested the relationships between various kinds of institutional and economic factors and corruption level, although many of them are based on the problematic measurement of corruption. Since the main focus of this study is to demonstrate the misleading results of using perception-based measurements to study the determinants of corruption rather than substantiating the causal relationships between institutional or economic factors and corruption, this paper will not highlight the latter part. The causal mechanisms of such relationships were well discussed in previous literature, while further studies on these relationships should be careful about the proposed theory. Most of the literature still hypothesizes each factor is associated with corruption level independently and in a linear way, which cannot be substantiated as fact.

\section{Estimation Strategy}

Previous discussions have demonstrated that the causal linkages between cultural traditions and corruption are not theoretically valid. At the same time, perceptionbased indicators of corruption, which are often found effectively predicted by various kinds of cultural tradition variables, are proven to be systematically biased. In light of this, I hypothesize that the apparent associations between cultural traditions and corruption are not causal inference but an artifact of the systematic measurement bias on the dependent variable. In other words, cultural tradition variables are correlated with measurement bias on perception-based indicators, rather than on corruption level itself.

The main strategy of the empirical examination is to find some measurement of corruption that can avoid the weaknesses, especially the measurement bias, that the CPI and CCI suffer, and regress it with the cultural tradition variables discussed above. If the associations are still significant, the causal effects may stand; while if the associations become insignificant, the causal effects of cultural traditions on corruption are spurious. For comparison, CCI and CPI are also regressed on the cultural tradition variables.

\subsection{The Alternative Measurement}

In this section, I will take advantage of an experience-based measurement of corruption with data from Transparency International's (TI) Global Corruption Barometer (GCB), to test the main argument of this paper. Although it also comes from TI, the source and methodology of this measurement are very different from those of CPI. In the survey of GCB, there is a question that asks: "In the past 12 months, have you or anyone living in your household paid a bribe in any form?" From the statistical results, we can acquire the data of the percentage of respondents 
Table 7 Summary statistics of Transparency International's data of bribe-paying rate

\begin{tabular}{lcllll}
\hline & No. obs. & Mean (\%) & SD (\%) & Min (\%) & Max (\%) \\
\hline 2006 & 61 & 13.6 & 15.2 & 1 & 66 \\
2007 & 50 & 18.6 & 20.8 & 1 & 79 \\
2009 & 65 & 17.2 & 18.4 & 1 & 87 \\
$2010 / 2011$ & 100 & 28.3 & 23.4 & 0.4 & 89 \\
2013 & 95 & 26.7 & 20.6 & 1 & 84 \\
All obs. & 371 & 22.3 & 21.0 & 0.4 & 89 \\
\hline
\end{tabular}

who reported paying a bribe in each country, and this occurrence rate of bribery is a good reflection of a country's corruption level.

This experience-based measurement of corruption is named Bribe-Paying Rate Index (BPR index) in this paper. Descriptive statistics of the data is presented in Table 7. The sample contains 371 observations from five different years, and the reported occurrence rate of bribery in the surveyed countries distributes falls 0.4 and $89 \%$ (Table 7).

The BPR index does not suffer the weaknesses that the CPI and CCI suffer. First, all the data are completely comparable with each other, both across countries and over years, since the concept of corruption is explicitly defined as bribery, and every observation comes from the same source. ${ }^{12}$ Second, since the measurement is experience based, it is much less likely to be contaminated by irrelevant subjective speculation - the bias in perception-based measurements. The survey also conformed to the principle of random sampling so there cannot be serious sample selection bias. Thirdly, there is no doubt that bribery is one of the main forms of corruption, and a bribe-paying rate can directly reflect the occurrence rate of corrupt behavior, so there is no problem of misrepresentation.

On the other hand, we must acknowledge that the BPR index is not perfect. Two points of consideration ought to be raised about it. First, it could be that not all respondents faithfully answered the question. Some respondents who had paid bribes during the past 12 months may not have reported it to the investigator due to ethical consideration or fear of punishment. Unfaithful responses can impose bias on the BPR, but I found the bias is not systematic. A systematic bias is most likely the result of social norms that are related to the tolerance of bribery, since people from societies that have a low tolerance for bribery are more likely to answer the question unfaithfully. However, my empirical testing shows that the bribery-tolerance cannot effectively predict the bribe-paying rate. ${ }^{13}$ Second, bribery is just one aspect of corruption, and the BPR index cannot represent the occurrence rate of all kinds of corruption. This critique is reasonable and should be noted. Nonetheless, so far there has been no indicator that can capture the overall situation of corruption across

\footnotetext{
12 There is only one simple question invariably asked to each respondent in each year. The content of the question is also essentially the same although there are subtle variations of phrasing in different years.

13 A question from the GCB survey asking "Have you refused to pay a bribe?" is used to measure a society's tolerance to bribe-paying. The reported bribe-paying rate and bribe-rejection rate in GCB 2013 are negatively correlated with a coefficient of -0.39 . I interpret this as a moderate association, but still not a strong association.
} 
many countries. CCI and CPI only capture bribes as well. Corruption in procurement and state capture are barely captured by the indexes (Knack 2006).

\subsection{Key Independent Variables}

British colonial tradition is a dummy variable capturing whether Britain used to be a primary colonial power of a country. Religious traditions include Protestant tradition, Catholic tradition, and Islamic tradition. They are measured by, first, whether or not the largest religion by population in each country is Protestantism/ Catholicism/Islam, and second, the percentage of the population in each country believing in Protestantism/Catholicism/Islam. ${ }^{14}$ Legal traditions include the British common law tradition, the French civil law tradition, the socialist law tradition, the German civil law tradition, and the Scandinavian law tradition. All these legal traditions are measured in the form of dummy variables. The data come from La Porta et al. (1999). Democratic tradition is a continuous variable measured by the number of consecutive years that a democratic regime had lasted. For example, on this variable, the United States is coded as 200 in 2009, and China is coded as 0 in 2009, while Iran is also coded as 0 in 2009 even though this country used to be a democracy. ${ }^{15}$ The original data come from the Polity IV Program.

\subsection{Control Variables}

The first category of control variables is political institutions, including institutional democracy and federal structure. ${ }^{16}$ Democracy is conceived as three essential, interdependent elements. One is the presence of institutions and procedures through which citizens can express effective preferences about alternative policies and leaders. Second is the existence of institutionalized constraints on the exercise of power by the executive. Third is the guarantee of civil liberties to all citizens in their daily lives and in acts of political participation. ${ }^{17}$ In practice, these principles are reflected in free elections, systems of checks and balances, as well as in rule of law. All of these institutional arrangements could help, to some extent, prevent public officials from abusing their power by revealing and punishing their misconduct. It is noteworthy that although it seems to be consensus among scholars that democracy is a reflection of the quality of institutions, and good institutions reduce corruption, relationships between institutional democracy and corruption revealed by previous literature are not always significant. Some observations also contradict the negative relationship between democracy and corruption. For example, Hong Kong and Singapore, with the cleanest

\footnotetext{
${ }^{14}$ Data for the dummy variables come from Cross-National Socio-Economic and Religion dataset, and data for the continuous variables come from Global Religious Futures by Pew Research Center.

15 A democracy which had broken-down is too weak to generate, maintain and leave the democratic culture, even if we acknowledge that long-established democracies do have a unique "democratic culture" which are good for controlling corruption. So I code countries like Iran as zero.

16 Freedom of press and political stability may also have effects on corruption level, while they are highly correlated with institutional democracy level. For avoiding multicollinearity, they are not controlled in the regressions.

17 See Polity IV Project: Dataset Users' Manual.
} 
governments in the world, are not full-fledged democracies. On the other hand, longestablished democracies like India and the Philippines are rather corrupt. In short, existent theory and evidence on the democracy-corruption nexus is not satisfying enough. Further discussion on this topic is not the main purpose of this paper. I only hypothesize that countries with a higher degree of democracy are less corrupt, with the assumption that democracy can to some extent reflect the quality of institutions. The data measuring democracy come from Polity IV Program.

Federal structure captures the extent of political and administrative decentralization, which has been found to be more corrupt than unitary systems in previous literature (see Treisman 2000). However, it is not very clear why federal systems have more corruption than unitary systems. Some argued that a unitary predatory government will moderate its demands, while if multiple officials regulate the same actors and fail to coordinate, they may set the total bribe rate higher than would be optimal for a unitary, bribe-maximizing government (Shleifer and Vishny 1993). On the other hand, local governments under a federal structure are closer to the electorates. The latter can hold local public officials accountable more directly and effectively compared with unitary systems where local officials are more of the agents of the central government. No matter which effect is true, federal or unitary structure represents an important institutional arrangement in a country that should be controlled in the analysis. In the regressions, federal structure is a dummy variable. The data come from the dataset of the Institutions and Elections Project.

The second category of control variable just includes economic development, which is measured by the natural logarithm of GNI per capita. Economic development increases education level, literacy, and depersonalized relationships, each of which should raise the odds that an abuse will be noticed and challenged (Treisman 2000).

The third set of control variables is economic structure and policy, including resource revenue and economic freedom. The resource revenue variable captures the extent to which a country's economy is dependent on the revenue of natural resources, which is measured by the total natural resource rent as a percentage of GDP. Some literature has found that dependence on natural resources increases corruption where institutions are weak (Bhattacharyya and Hodler 2010; Vicente 2010). The resource revenue data come from the WDI dataset. Economic freedom is represented by business freedom, which captures the number of procedures and time it takes to start a business in each country. A lack of business freedom means the government exerts more regulations on enterprises than an optimum standard, which gives public officials more opportunities to solicit bribes. The data measuring business freedom come from The Heritage Foundation.

In addition, although some literature argues that economic openness has an effect on corruption levels, the preliminary regression shows the association between import dependency, measured by import as a percentage of GDP, and the occurrence rate of bribery is not significant, so this variable is not controlled.

Summary statistics of the data on the dependent variables, key independent variables, as well as control variables are presented in Table 8. 
Table 8 Summary statistics of the variables

\begin{tabular}{llcccc}
\hline Variable name & No. obs. & Mean & SD & Min & Max \\
\hline Bribe-paying rate & 371 & 0.22 & 0.21 & 0 & 0.89 \\
Control of corruption & 369 & 0.13 & 1.10 & -1.62 & 2.55 \\
Corruption perception index & 359 & 4.59 & 2.33 & 0.8 & 9.6 \\
Institutional democracy & 342 & 6.61 & 4.54 & -7 & 10 \\
Federal structure & 335 & 0.49 & 0.50 & 0 & 1 \\
Ln (GNI per capita) & 352 & 9.27 & 1.13 & 6.29 & 11.43 \\
Resource revenue & 366 & 7.87 & 11.45 & 0 & 77.29 \\
Business freedom & 355 & 69.93 & 15.84 & 30 & 99.9 \\
British colonial tradition & 369 & 0.25 & 0.43 & 0 & 1 \\
Protestant religious tradition & 367 & 0.09 & 0.29 & 0 & 1 \\
& 369 & 0.19 & 0.25 & 0.00 & 0.91 \\
Catholic religious tradition & 367 & 0.32 & 0.47 & 0 & 1 \\
& 369 & 0.27 & 0.32 & 0.00 & 0.92 \\
Islamic religious tradition & 367 & 0.20 & 0.40 & 0 & 1 \\
& 369 & 0.21 & 0.33 & 0.01 & 0.99 \\
British legal tradition & 357 & 0.29 & 0.45 & 0 & 1 \\
French legal tradition & 357 & 0.35 & 0.48 & 0 & 1 \\
Socialist legal tradition & 357 & 0.24 & 0.42 & 0 & 1 \\
German legal tradition & 357 & 0.07 & 0.25 & 0 & 1 \\
Scandinavian legal tradition & 357 & 0.06 & 0.23 & 0 & 1 \\
Democratic tradition & 352 & 29.32 & 38.98 & 0 & 204 \\
\hline & & & & & \\
\hline
\end{tabular}

\section{Results and Analysis}

In this section, the BPR index, CCI and CPI are, respectively, regressed on the key independent variables, with democracy, federal structure, logarithm of GNI per capita, resource revenue, and business freedom being controlled. The regressions are classified into five different specifications, each of which has identical independent variables but different dependent variables, in order to compare the results of regressing BPR and those of regressing CPI. To present a more comparable pattern of the regression results, BPR and CPI are standardized, both of which vary between 0 and 100, and higher values represent more corruption. Random effect regression is used for the estimation since the data are in the form of panel. Fixed effect regression is not considered because most of the key independent variables rarely vary across different years. The results of the regressions are presented in Table 9. Since regressing CPI and CCI on the same independent variables can get very similar results, I only report the results of regressing CPI.

Results of the first specification [column (1) and (2)] show that a British colonial tradition can increase the bribe-paying rate by $3.5 \%$, while it also reduces perceived corruption by $5 \%$. However, none of the results are significant, which means the correlations between the British colonial tradition and corruption are not robust under different specifications or different measurements of corruption. 


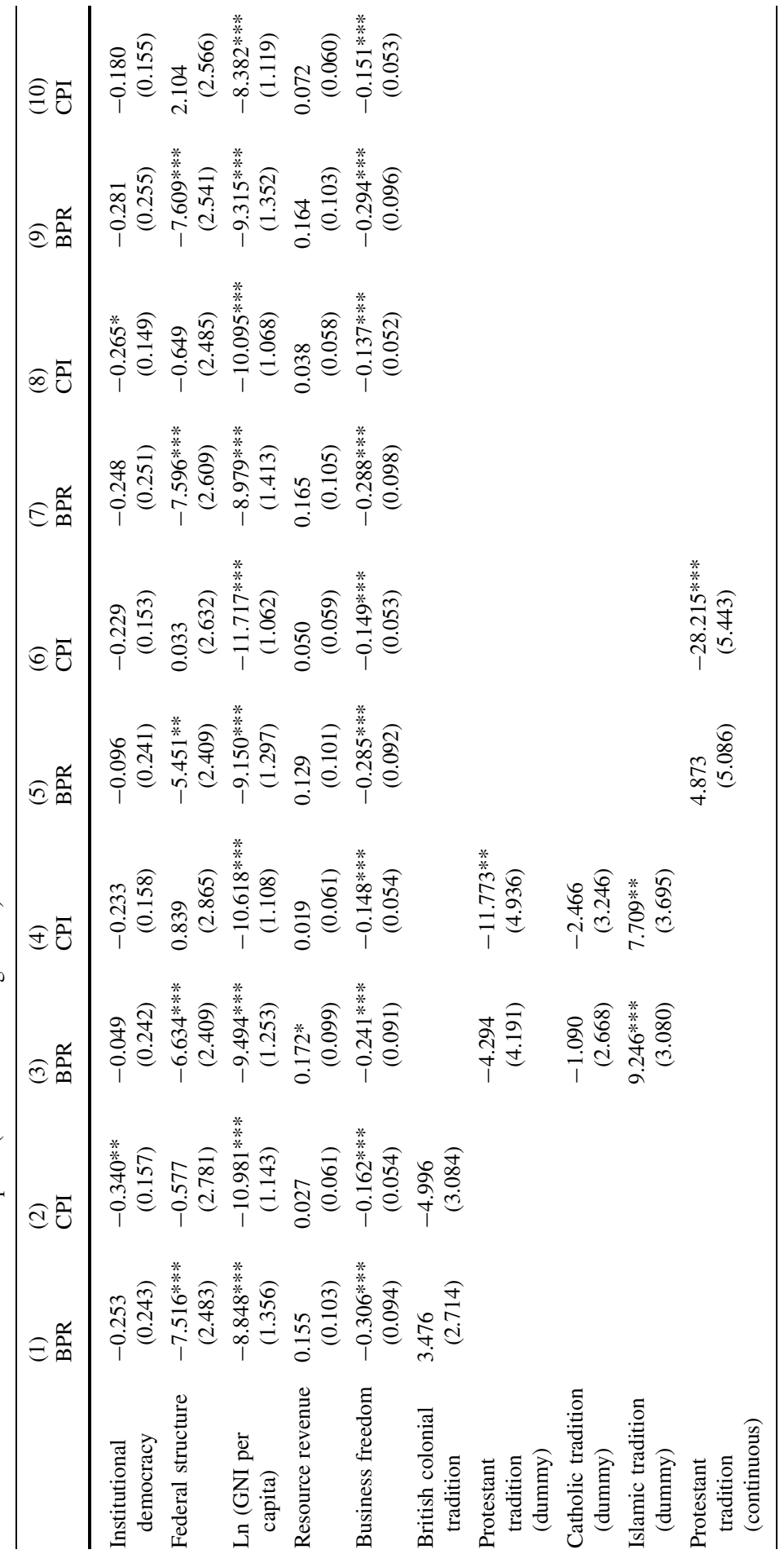




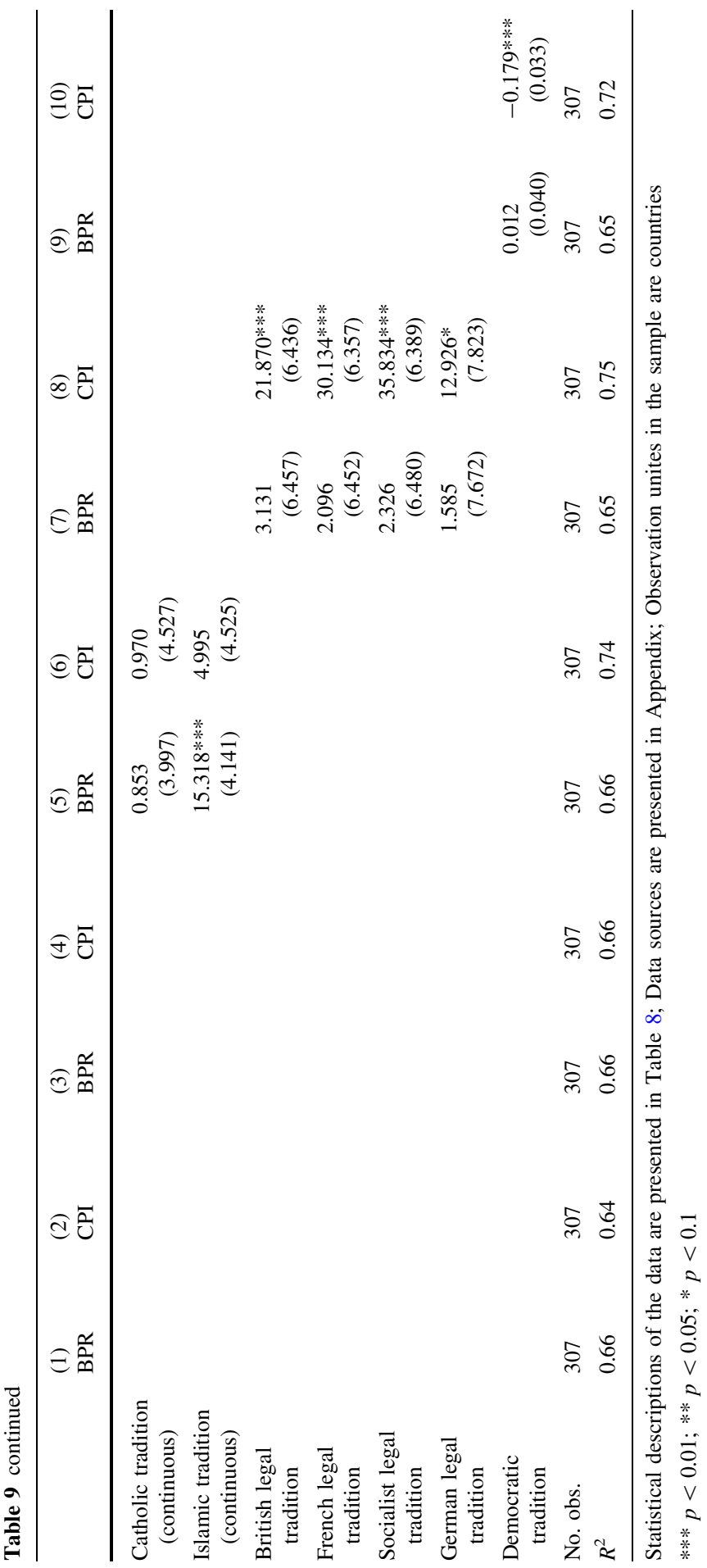


In regression (3) to (6), BPR index and CPI are, respectively, regressed on three different kinds of religious tradition. The results show that a Protestant tradition can significantly reduce perceived corruption by $12 \%$, while the relationship between a Protestant tradition and the bribe-paying rate turn out to be insignificant. A Catholic tradition is not a significant predictor of either perceived corruption or the bribepaying rate. However, the Islamic tradition is significantly associated with the bribepaying rate. Countries with Islamic traditions have a higher bribe-paying rate compared with other countries. For example, the result of regression (3) shows that the bribe-paying rate in Islamic countries is about $9 \%$ higher than in non-Islamic countries. The results are consistent when religious traditions are measured in a different way [see regression (5)]. Nonetheless, the significance does not necessarily mean the Islamic tradition is the cause of corruption. The causal mechanism linking the Islamic tradition and corruption, as proposed in previous literature, has a mediating variable-interventionism. If this mechanism were valid, controlling business freedom in the regression would reduce the negative effect of an Islamic cultural tradition on control of corruption. However, when independent variable business freedom is removed from regression (3) or (5), the coefficient of Islamic tradition exhibits a tiny decrease, which seems to be contrary to the proposed theory linking corruption to Islamic tradition. Hence, the proposed causal relationship between Islamic tradition and corruption is spurious. It is possible that Islamic tradition leads to corruption in another way, but the specific causal mechanism needs to be further explored.

In regression (7) and (8), the relations between different kinds of legal traditions and corruption are tested. Results show that the British legal tradition, French legal tradition, and socialist legal tradition could significantly increase a country's perceived corruption level, respectively, by 22,30 , and $36 \%$. The result is not very consistent with the theories proposed in previous literature, which presume the British legal tradition can help reduce corruption rather than increase it. On the other hand, none of these legal traditions is significantly associated with the bribe-paying rate. The proposed causal relationships between legal traditions and corruption are also spurious.

Regression (9) and (10) test the relationship between democratic tradition and corruption. Results show that a 10-year increase of democratic experience could reduce perceived corruption levels by $1.8 \%$. However, the relationship between democratic tradition and bribe-paying rate is not significant. The association between democratic tradition and corruption may be nonlinear, which explains why it is not significant in regression (9).

To test the proposed nonlinear relationship between democratic tradition and corruption, I regress the BPR index on the natural logarithmic form of democratic tradition, with institutional democracy, federal structure, resource revenue, business freedom, and GNI per capita being controlled. The results are presented in Table 10. The coefficients of democratic tradition are significant in the first two regressions, but when business freedom and GNI per capita are controlled, the coefficients of democratic tradition become insignificant. In addition, as more variables are controlled in the regression, the coefficient of democratic tradition continues diminishing. These results indicate that the nonlinear relationship between 
Table 10 Democratic tradition (logarithm) and corruption (random effect regression)

\begin{tabular}{lcccc}
\hline \multicolumn{5}{c}{ Dependent variable: bribe-paying rate } \\
\hline Ln (democratic & $-6.338^{* * *}$ & $-3.598^{* * *}$ & $-1.314(1.337)$ & $0.416(1.283)$ \\
$\quad$ tradition) & $(1.310)$ & $(1.373)$ & & \\
Institutional & & $-3.064^{* * *}$ & $-1.445^{*}(0.746)$ & $-0.548(0.688)$ \\
$\quad$ democracy & & $(0.758)$ & & \\
Federal structure & & $-9.644 * * *$ & $-10.275^{* * *}$ & $-6.688^{* *}$ \\
& $(3.582)$ & $(3.104)$ & $(2.687)$ \\
Resource revenue & & $0.188(0.136)$ & $0.021(0.128)$ \\
Business freedom & & $-0.577^{* * *}$ & $-0.311^{* * *}$ \\
& & & $(0.104)$ & $(0.103)$ \\
GNI per capita & & & $-9.674^{* * *}$ \\
& & & 265 & $(1.765)$ \\
No. obs. & 265 & 265 & 0.50 & 265 \\
$R^{2}$ & 0.29 & 0.37 & 0.64 \\
\hline
\end{tabular}

Statistical descriptions of the data is presented in Table 8; Data sources are presented in Appendix; Observation unites in the sample are countries

*** $p<0.01 ; * * p<0.05 ; * p<0.1$

democratic tradition and corruption is not robust either. Long-established democracies just coincide with many other country attributes that have positive effects on corruption prevention. When these country attributes are controlled, the apparent association between democratic tradition and corruption disappears.

I further test the relationship between democratic tradition and corruption by recoding democratic tradition as dummy variables, as previous researchers did (see Treisman 2000). The dummy variables capture whether a democratic regime lasted uninterruptedly for a specific number of years. BPR index and CPI are, respectively, regressed on the dummy variables of democratic tradition with some other variables being controlled. The results in Table 11 show that democratic tradition coded as dummy variables is not significantly associated with bribe-paying rate, while the correlations between democratic tradition and perceived corruption are generally significant. For example, an experience of being democratic uninterruptedly for more than 40 years could help reduce perceived corruption levels by $9 \%$. Even so, it is noteworthy that democratic experience only has effect on perceived corruption, rather than the reality of corruption.

As for the control variables, regression results show that federal structure, GNI per capita, and business freedom are significantly associated with bribe-paying rate, and the associations are robust as specifications change. Specifically, federal structure could reduce corruption by 5-8\% compared with other forms of governmental structure. This result is contrary to previous research conclusions, which claim a positive association between federal structure and corruption. Increase in GNI per capita and business freedom also help reduce corruption. A $10 \%$ increase of business freedom could reduce the bribe-paying rate by $2.4-3 \%$. On the other hand, the association between democracy and bribe-paying rates is not 


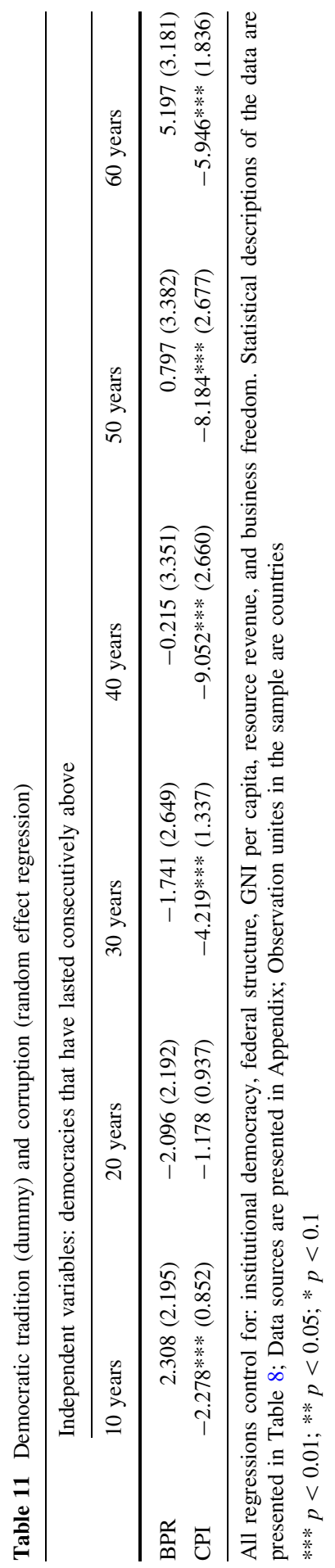


significant. The relationship between resource revenue and bribe-paying rates is not significant either.

\section{Further Discussion}

While there is distinctive contrast between regression results based on CPI and BPR, it is still not certain that the significant associations between cultural traditions and CPI are results of perception bias, unless it can be proven that cultural traditions are significantly associated with the measurement bias on CPI or CCI. To test whether cultural traditions are associated with the measurement bias on corruption or corruption itself, we need to materialize the measurement bias on CPI or CCI, which is reflected by the deviation of the corruption level measured by CPI or CCI from the corruption level measured by BPR. While the bribe-paying rate is not a perfect measurement of corruption level, it is much better at capturing the factual occurrence rate of corruption than perception-based measurements. In addition, as I argued previously, the discrepancy between perception-based indicators and experience-based indicators is not the result of different definitions of corruption. It is more likely the result of measurement bias on the perception-based indicators.

To calculate the measurement bias, the values of CPI, CCI, and BPR are standardized, all of which vary between 0 and 10 . The higher the value is, the more corrupt the country is. Then the standardized values of BPR are, respectively, subtracted from the values of CPI and CCI. The higher the absolute value is, the more extensive the measurement bias is. The measurement bias of CPI is highly correlated with that of CCI. In addition, countries' corruption levels measured by perception-based indicators are extensively higher than those measured by BPR index. The maximum extent of overestimation could reach seven points on a tenpoint variable.

To examine whether the cultural tradition variables can explain the measurement bias related to perception, the measurement bias on CPI is regressed on the cultural tradition variables that are found to be significantly associated with CPI in Table 9, with institutional democracy, GNI per capita, and business freedom being controlled. Regression results are presented in Table 12. The result shows Protestant religious tradition, socialist legal tradition, and democratic tradition are significantly associated with the measurement bias on CPI. Protestant religious tradition and democratic tradition are negatively associated with the measurement bias on CPI, which means these cultural traditions can reduce the overestimation of a country's corruption level. The effects hold when other country attributes are controlled. Perception-based indicators of corruption do systematically underestimate the corruption level of Protestant countries and long-established democracies, although no robust evidence has been found that these cultural endowments could affect corruption reality in this study. 
Table 12 Measurement bias on CPI and cultural traditions (OLS regression)

\begin{tabular}{|c|c|c|c|c|c|}
\hline & \multicolumn{5}{|c|}{ Dependent variable: the measurement bias on CPI } \\
\hline & (1) & (2) & (3) & (4) & $(5)$ \\
\hline Institutional democracy & $0.014(0.045)$ & $\begin{array}{r}-0.006 \\
(0.053)\end{array}$ & $\begin{array}{r}-0.001 \\
(0.054)\end{array}$ & $0.002(0.052)$ & $\begin{array}{l}0.048 \\
\quad(0.054)\end{array}$ \\
\hline Ln (GNI per capita) & $0.047(0.242)$ & $\begin{array}{l}0.207 \\
\quad(0.230)\end{array}$ & $\begin{array}{l}0.303 \\
\quad(0.291)\end{array}$ & $0.341(0.273)$ & $\begin{array}{l}0.506^{*} \\
(0.272)\end{array}$ \\
\hline Business freedom & $\begin{array}{r}-0.031 * \\
(0.018)\end{array}$ & $\begin{array}{c}-0.052 * * \\
(0.022)\end{array}$ & $\begin{array}{c}-0.055^{* *} \\
(0.022)\end{array}$ & $\begin{array}{c}-0.054 * * * \\
(0.021)\end{array}$ & $\begin{array}{c}-0.046^{* *} \\
(0.020)\end{array}$ \\
\hline $\begin{array}{l}\text { Protestant tradition } \\
\text { (continuous) }\end{array}$ & $\begin{array}{c}-4.231 * * * \\
(0.887)\end{array}$ & & & & \\
\hline British legal tradition & & $\begin{array}{r}-0.745 \\
(0.578)\end{array}$ & & & \\
\hline French legal tradition & & & $\begin{array}{l}0.350 \\
\quad(0.539)\end{array}$ & & \\
\hline Socialist legal tradition & & & & $\begin{array}{l}1.000 * \\
(0.512)\end{array}$ & \\
\hline Democratic tradition & & & & & $\begin{array}{c}-0.018 * * \\
(0.007)\end{array}$ \\
\hline No. obs. & 58 & 57 & 57 & 57 & 58 \\
\hline$R^{2}$ & 0.40 & 0.17 & 0.15 & 0.20 & 0.23 \\
\hline
\end{tabular}

The data used for the regressions are cross-sectional data on observing year 2009, which is a part of the panel data used for the main regressions of this paper. Data sources are presented in Appendix

$* * * p<0.01 ; * * p<0.05 ; * p<0.1$

\section{Conclusion}

Previous cross-national studies on determinants of corruption commonly share the feature of depending on perception-based aggregated indicators. While researchers have pointed out the serious weaknesses that perception-based data may suffer, little awareness has been raised. Studies of this line of research have rarely diverged from the track of measuring corruption by perception rather than by experience. In light of this persistent shortcoming, this study attempts to emphasize the costs of dependence on perception-based data in cross-national studies on corruption, not just probing into the weaknesses of the data, but also further demonstrating variance in corruption levels can be mistakenly attributed to cultural traditions when regressions are grounded in perception-based measurements.

This study first discussed and examined the weaknesses that perception-based measurement of corruption commonly suffers, taking the widely used cross-national corruption indicators Corruption Perception Index and Control of Corruption as examples. This paper demonstrated first that data on perception-based indicators of corruption are not comparable with each other due to the variance in sources for different observations; second, perception-based indicators are systematically biased, and this is primarily the result of the intrinsically subjective nature of perceptual assessment. That systemic bias may well be the main reason that perceived corruption was often found to be correlated with factors that are not 
supposed to be associated with corruption reality. Third, corruption levels measured by perception-based indicators substantially deviate from experience-based measurements. That deviation is not likely the result of a different definition of corruption, but rather the result of different methods of measuring corruption. All these weaknesses make perception-based measurement of corruption biased, and biased data cannot generate valid regression results.

This study then re-examined the relationships between different cultural traditions and corruption, which were commonly found to be significantly correlated in literature that used perception-based data to measure corruption. I first tested the causal mechanisms that attribute corruption to several cultural traditions, including colonial traditions, religious traditions, legal traditions, as well as democratic traditions. I found most of the causal mechanisms between different cultural traditions and corruption were not as valid as proposed by other scholars. Second, I regressed an experience-based measurement of corruption on the cultural traditions to observe the proposed causal effects. When perception-based indicators are substituted with the experience-based indicator, which does not suffer the weaknesses that perception-based indicators do, the apparent correlation between cultural traditions and corruption mostly disappeared.

To explain the pattern of cultural traditions commonly being correlated with perceived corruption but not experienced corruption, I argued that it was the perceptual bias of a perception-based index that was associated with cultural traditions, not corruption reality itself. This argument was proved plausible when the measurement bias of a perception-based index was regressed on cultural traditions, since some of the results were significant. It could be that respondents' perceptions of corruption are to some extent based on cultural traditions or some other highly correlated attributes of a country, although no robust evidence has been offered that these factors do have causal effects on actual levels of corruption. In other words, the apparent associations between cultural traditions and the perception-based indicators of corruption may not be positive causal inference, but rather the causal inference that exists in the mind of the respondents whose perception was used to measure corruption.

In addition to the primary findings, some other results also deserve attention. First, the Islamic cultural tradition was found to be significantly associated with bribery rates - the only significant correlation in the regression results. Although the proposed causal mechanism to support such causal inference was proved to be invalid, further study could explore other possible causal explanations and test the robustness of such statistical associations in other specifications. Second, the relationship between institutional democracy and bribery rates is not robust, although the theory that democracy helps curb corruption has become quite influential. There may be elements of truth in this theory, but the theory itself may not be as simple as has been proposed in previous quantitative literature. Further research could explore the specific conditions under which democracy can hold public officials accountable. Third, federal structure was found to be negatively and robustly associated with bribery rates, which contradicted common findings in previous research. This indicates that relationships between decentralization and corruption are even more complicated. Last, dependence on resource revenue did 
not appear to be a good predictor of a country's corruption level, at least not in a linear way.

Acknowledgments The author would like to thank Professor Yijia Jing for his kind instruction and guidance during the writing of this paper. The author is also grateful for helpful comments and advice from three anonymous reviewers at the journal. Part of this work was completed while the China Scholarship Council supported its author.

\section{Appendix}

See Table 13.

Table 13 Sources of the data

\begin{tabular}{|c|c|c|}
\hline Variable & Explanation & Source \\
\hline $\begin{array}{l}\text { Bribe-paying } \\
\text { index }\end{array}$ & $\begin{array}{l}\text { Range between } 0 \text { and } 1 \text {, the value is higher, } \\
\text { bribe-paying rate is higher }\end{array}$ & $\begin{array}{l}\text { Global corruption barometer, } \\
\text { transparency international }\end{array}$ \\
\hline $\begin{array}{l}\text { Corruption } \\
\text { perception } \\
\text { index }\end{array}$ & $\begin{array}{l}\text { Range between } 0 \text { and } 10 \text {, the value is higher, } \\
\text { corruption level is lower }\end{array}$ & Transparency international \\
\hline $\begin{array}{l}\text { Control of } \\
\text { corruption } \\
\text { index }\end{array}$ & $\begin{array}{l}\text { Range between }-2.5 \text { and } 2.5 \text {, the value is } \\
\text { higher, corruption level is lower }\end{array}$ & $\begin{array}{l}\text { Worldwide governance indicators, } \\
\text { World bank }\end{array}$ \\
\hline $\begin{array}{l}\text { Institutional } \\
\text { democracy }\end{array}$ & $\begin{array}{l}\text { Range between }-10 \text { and } 10 \text {, the value is } \\
\text { higher, it is more democratic }\end{array}$ & Polity IV, Center for systematic peace \\
\hline $\begin{array}{l}\text { Federal } \\
\text { structure }\end{array}$ & $\begin{array}{l}\text { Dummy variable with } 1 \text { representing countries } \\
\text { have a federal structure }\end{array}$ & $\begin{array}{l}\text { Institutions and Elections Project, } \\
\text { Binghamton University }\end{array}$ \\
\hline $\begin{array}{l}\text { GNI per } \\
\text { capita }\end{array}$ & $\begin{array}{l}\text { Range above } 0 \text {, the value is higher, the income } \\
\text { is higher }\end{array}$ & $\begin{array}{l}\text { World development indicators, World } \\
\text { Bank }\end{array}$ \\
\hline $\begin{array}{l}\text { Resource } \\
\text { revenue } \\
\text { dependence }\end{array}$ & $\begin{array}{l}\text { Range between } 0 \text { and } 1 \text {, the value is higher, } \\
\text { the country is more dependent on resource } \\
\text { revenue }\end{array}$ & $\begin{array}{l}\text { World development indicators, World } \\
\text { Bank }\end{array}$ \\
\hline $\begin{array}{l}\text { Business } \\
\text { freedom }\end{array}$ & $\begin{array}{l}\text { Range between } 0 \text { and } 100 \text {, the value is higher, } \\
\text { there is more freedom }\end{array}$ & Heritage foundation \\
\hline $\begin{array}{l}\text { British } \\
\text { colonial } \\
\text { tradition }\end{array}$ & $\begin{array}{l}\text { Dummy variable with } 1 \text { representing countries } \\
\text { as former British colonies }\end{array}$ & $\begin{array}{l}\text { ICOW colonial history data set, Paul } \\
\text { R. Hensel }\end{array}$ \\
\hline $\begin{array}{l}\text { Religious } \\
\text { traditions } \\
\text { (dummy) }\end{array}$ & $\begin{array}{l}\text { Dummy variable with } 1 \text { representing countries } \\
\text { whose largest religion is Protestant/Catholic/ } \\
\text { Islam }\end{array}$ & $\begin{array}{l}\text { Cross-national socio-economic and } \\
\text { religion data, Association of religion } \\
\text { data archives }\end{array}$ \\
\hline $\begin{array}{l}\text { Religious } \\
\text { tradition } \\
\text { (continuous) }\end{array}$ & $\begin{array}{l}\text { Range between } 0 \text { and } 1 \text {, the value is higher, } \\
\text { the percentage of Protestant/Catholic/Islam } \\
\text { populations is higher }\end{array}$ & $\begin{array}{l}\text { Global religious futures, Pew Research } \\
\text { Center }\end{array}$ \\
\hline $\begin{array}{l}\text { Legal } \\
\text { traditions }\end{array}$ & $\begin{array}{l}\text { Dummy variable with one representing } \\
\text { countries have common law/French law/ } \\
\text { German law/Scandinavian law/Socialist law } \\
\text { tradition }\end{array}$ & Porta et al. (1999) \\
\hline $\begin{array}{l}\text { Democratic } \\
\text { tradition }\end{array}$ & $\begin{array}{l}\text { Range above } 0 \text {, higher value represent more } \\
\text { democratic tradition }\end{array}$ & Polity IV, Center for systematic peace \\
\hline
\end{tabular}




\section{References}

Abramo, Claudio Weber. 2008. How much do perceptions of corruption really tell us? Economics: The Open-Access, Open-Assessment E-Journal 2(3): 1-56.

Andersson, Staffan, and Paul M. Heywood. 2009. The politics of perception: Use and abuse of Transparency International's approach to measuring corruption. Political Studies 57(4): 746-767.

Bai, Ying, and James Kai-sing Kung. 2015. Diffusing knowledge while spreading God's message: Protestantism and economic prosperity in China, 1840-1920. Journal of the European Economic Association 13: 669-698.

Barr, Abigail, and Danila Serra. 2010. Corruption and culture: An experimental analysis. Journal of Public Economics 94(11): 862-869.

Becker, S.O., and L. Woessmann. 2009. Was Weber wrong? A human capital theory of Protestant economic history. The Quarterly Journal of Economics 124(2): 531-596.

Bhattacharyya, Sambit, and Roland Hodler. 2010. Natural resources, democracy and corruption. European Economic Review 54(4): 608-621.

Bohara, Alok K., Neil J. Mitchell, and Carl F. Mittendorff. 2004. Compound democracy and the control of corruption: A cross-country investigation. Policy Studies Journal 32(4): 481-499.

Brunetti, Aymo, and Beatrice Weder. 2003. A free press is bad news for corruption. Journal of Public Economics 87(7): 1801-1824.

Cantoni, Davide. 2015. The economic effects of the protestant reformation: Testing the Weber hypothesis in the German lands. Journal of the European Economic Association 13: 561-598.

Chowdhury, Shyamal K. 2004. The effect of democracy and press freedom on corruption: An empirical test. Economics Letters 85(1): 93-101.

Fan, C.Simon, Chen Lin, and Daniel Treisman. 2009. Political decentralization and corruption: Evidence from around the world. Journal of Public Economics 93(1): 14-34.

Gerring, John, and Strom C. Thacker. 2005. Do neoliberal policies deter political corruption? International Organization 59(1): 233-254.

Glaeser, Edward L., and Claudia Goldin. 2007. Corruption and reform: Lessons from America's economic history. Chicago: University of Chicago Press.

Goldsmith, Arthur A. 1999. Slapping the grasping hand. American Journal of Economics and Sociology 58(4): 865-883.

Kaufmann, Daniel, Aart Kraay, and Massimo Mastruzzi. 2007a. Growth and governance: A reply. Journal of Politics 69(2): 555-562.

Kaufmann, Daniel, Aart Kraay, and Massimo Mastruzzi. 2007b. Growth and governance: A rejoinder. Journal of Politics 69(2): 570-572.

Knack, Stephen. 2006. Measuring corruption in Eastern Europe and Central Asia: A critique of the crosscountry indicators. World Bank Policy Research Working Paper No. 3968.

Kolstad, Ivar, and Arne Wiig. 2015. Does democracy reduce corruption? Democratization 1-21.

Kurtz, Marcus J., and Andrew Schrank. 2007a. Growth and governance: Models, measures, and mechanisms. Journal of Politics 69(2): 538-554.

Kurtz, Marcus J., and Andrew Schrank. 2007b. Growth and governance: A defense. Journal of Politics 69(2): 563-569.

Lederman, Daniel, Norman V. Loayza, and Rodrigo R. Soares. 2005. Accountability and corruption: Political institutions matter. Economics and Politics 17(1): 1-35.

McKinnon, Andrew M. 2010. Elective affinities of the Protestant ethic: Weber and the chemistry of capitalism. Sociological Theory 28(1): 108-126.

Mensah, Yaw M. 2014. An analysis of the effect of culture and religion on perceived corruption in a global context. Journal of Business Ethics 121(2): 255-282.

Montinola, Gabriella R., and Robert W. Jackman. 2002. Sources of corruption: A cross-country study. British Journal of Political Science 32(1): 147-170.

Olken, B.A. 2009. Corruption perceptions vs. corruption reality. Journal of Public Economics 93(7): 950-964.

Pellegrini, Lorenzo, and Reyer Gerlagh. 2008. Causes of corruption: A survey of cross-country analyses and extended results. Economics of Governance 9(3): 245-263.

Porta, La, Florencio Lopez-de-Silanes Rafael, Andrei Shleifer, and Robert Vishny. 1999. The quality of government. Journal of Law Economics and Organization 15(1): 222-279. 
Razafindrakoto, Mireille, and François Roubaud. 2010. Are international databases on corruption reliable? A comparison of expert opinion surveys and household surveys in Sub-Saharan Africa. World Development 38(8): 1057-1069.

Rock, Michael T. 2009. Corruption and democracy. Journal of Development Studies 45(1): 55-75.

Saha, Shrabani, Rukmani Gounder, Neil Campbell, and J.J. Su. 2014. Democracy and corruption: A complex relationship. Crime, Law and Social Change 61(3): 287-308.

Sandholtz, Wayne, and William Koetzle. 2000. Accounting for corruption: Economic structure, democracy, and trade. International Studies Quarterly 44(1): 31-50.

Serra, Danila. 2006. Empirical determinants of corruption: A sensitivity analysis. Public Choice 126(1-2): 225-256.

Shleifer, Andrei, and Robert W. Vishny. 1993. Corruption. Quarterly Journal of Economics 108(3): 599-618.

Sung, Hung-en. 2004. Democracy and political corruption: A cross-national comparison. Crime, Law and Social Change 41(2): 179-193.

Thomas, Melissa A. 2010. What do the worldwide governance indicators measure? European Journal of Development Research 22(1): 31-54.

Treisman, Daniel. 2000. The causes of corruption: A cross-national study. Journal of Public Economics 76(3): 399-457.

Treisman, Daniel. 2007. What have we learned about the causes of corruption from ten years of crossnational empirical research? Annual Review of Political Science 10: 211-244.

Vicente, Pedro C. 2010. Does oil corrupt? Evidence from a natural experiment in West Africa. Journal of Development Economics 92(1): 28-38.

Wilhelm, Paul G. 2002. International validation of the corruption perceptions index: Implications for business ethics and entrepreneurship education. Journal of Business Ethics 35(3): 177-189.

Zhong, Yang, and Yongguo Chen. 2013. Regime support in urban China. Asian Survey 53(2): 369-392.

Ning He is currently a graduate student at the School of International Relations and Public Affairs (SIRPA), Fudan University, Shanghai, China. 